\title{
The Fear-Avoidance Model of Pain
}

Johan W.S. Vlaeyen, Geert Crombez, Steven J. Linton

The large individual variations in response to a similar nociceptive stimulus, as well as the development of persistent pain after an acute pain episode have puzzled researchers and clinicians alike. The Fear-Avoidance model has been introduced as a theoretical model to guide pain research and management, describing the cascade of events following pain that is perceived as threatening [5].

\section{Acquisition and generalization}

Fear is the anticipatory emotional response to imminent threat, and adaptive learning takes place rapidly, either via direct experience[3], observation[2], or verbal instructions. Initial neutral cues (conditioned stimuli, CS) causally or functionally associated with pain may capture the attention and elicit protective fear responses (conditioned responses), such as avoidance [4]. Learning typically occurs with interoceptive or proprioceptive CSs. Chronic pain may develop when pain-related fear and avoidance persists despite healing, or when protective responses generalize to novel situations (GS) that share features with the CS. Avoidance usually implies activity restrictions, interference with valued life activities, and negative affect. Avoidance can be used as a source of information to derive danger, for example: "I am avoiding, therefore there must be danger. The relief that the expected threat did not occur may reinforce avoidance behaviors, and hence maintaining it.

\section{Pain in context}

Pain-related fear is not always associated with avoidance behavior. The expression of pain-related fear and avoidance behavior is dependent on context. The goal to avoid pain is only one to be pursued in an environment with concomitant, often competing goals [1]. Fear-related protective behaviors are inhibited when the value of another life goal outweighs the value of pain, and is given priority. Negative affect and harm representations may increase the engagement in pain control, while positive affect and optimism may foster the priority to valued life goals.

\section{Extinction of pain-related fear}

Inhibitory responses can be learned when avoidance behavior is omitted, and the individual is exposed to the stimuli and situations that were previously avoided. In such exposure treatments, new non-threat associations with the Cs's are formed, and subsequently may generalize across time and contexts [6]. In contrast to its acquisition, the extinction of pain-related fear is fragile, context-dependent, and it does not easily generalize to novel situations.

\section{References}

[1] Crombez G, Eccleston C, Van Damme S, Vlaeyen JW, Karoly P. Fear-avoidance model of chronic pain: the next generation. The Clinical journal of pain 2012;28(6):475-483.

[2] Goubert L, Vlaeyen JW, Crombez G, Craig KD. Learning about pain from others: an observational learning account. The journal of pain : official journal of the American Pain Society 2011;12(2):167174.

[3] Meulders A, Vlaeyen JW. The acquisition and generalization of cued and contextual pain-related fear: an experimental study using a voluntary movement paradigm. Pain 2013;154(2):272-282.

[4] Vlaeyen JW. Learning to predict and control harmful events: chronic pain and conditioning. Pain 2015;156 Suppl 1:S86-93.

[5] Vlaeyen JW, Linton SJ. Fear-avoidance model of chronic musculoskeletal pain: 12 years on. Pain 2012;153(6):1144-1147.

[6] Vlaeyen JW, Morley S, Linton S, Boersma K, De Jong J. Pain-Related Fear: Exposure-Based Treatment for Chronic Pain. Seattle: IASP Press, 2012. 
Acknowledgements

This work was supported by the Methusalem Grant "Asthenes" to JWSV (METH/15/011), and Grant G091812N to JWSV and GC by the Research Foundation-Flanders, Belgium (Fonds Wetenschappelijk Onderzoek [FWO] Vlaanderen) 

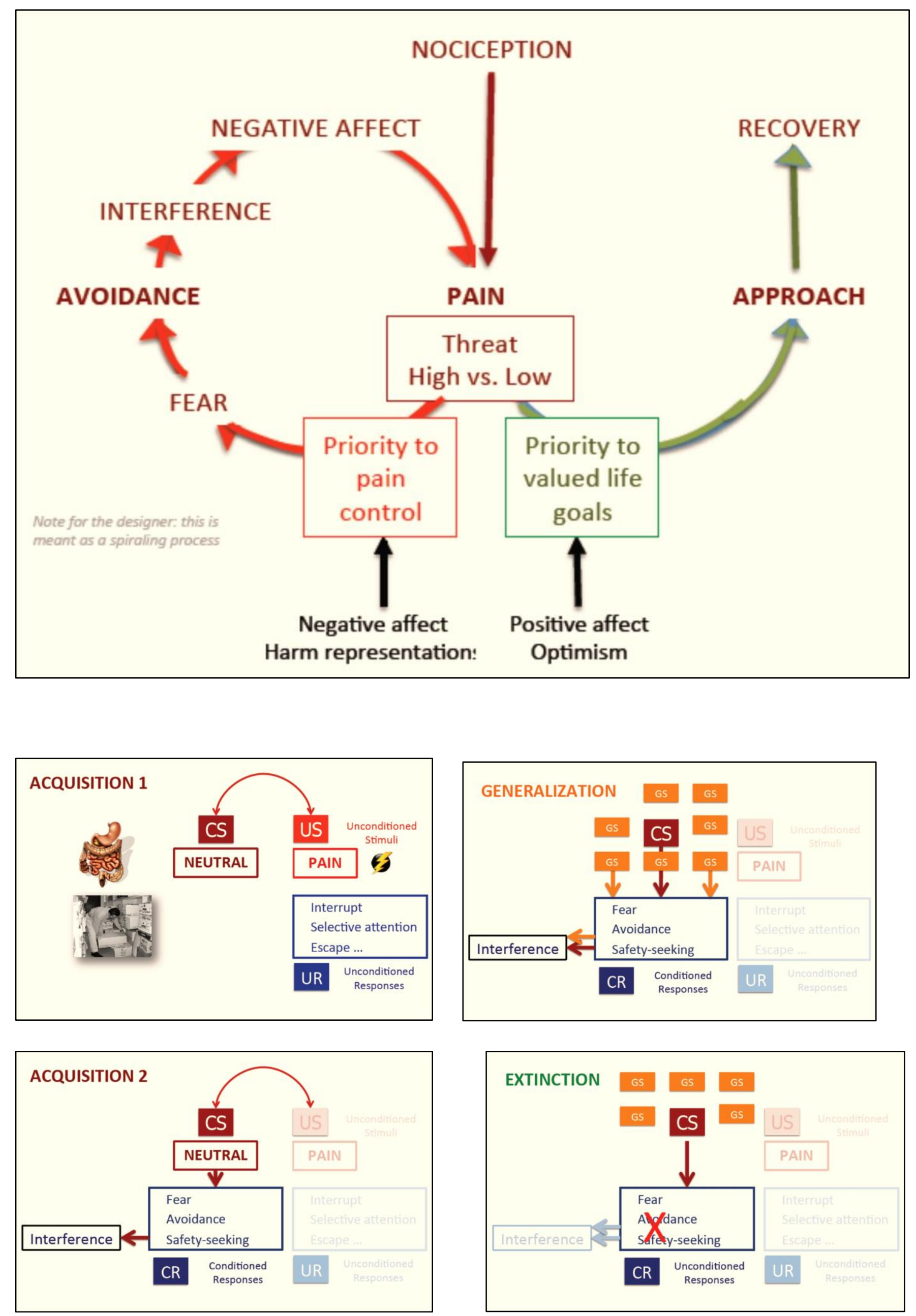
